\title{
Nanoparticulate Adjuvants and Delivery Systems for Allergen Immunotherapy
}

\author{
Juliana De Souza Rebouças, ${ }^{1}$ Irene Esparza, ${ }^{1}$ Marta Ferrer, ${ }^{2}$ María Luisa Sanz, ${ }^{2}$ \\ Juan Manuel Irache, ${ }^{1}$ and Carlos Gamazo ${ }^{1}$ \\ ${ }^{1}$ Adjuvant Unit, Department of Pharmacy and Pharmaceutical Technology, and Department of Microbiology, University of Navarra, \\ 31008 Pamplona, Spain \\ ${ }^{2}$ Department of Allergy and Clinical Immunology, Clinica Universidad de Navarra, 31008 Pamplona, Spain
}

Correspondence should be addressed to Carlos Gamazo, cgamazo@unav.es

Received 1 September 2011; Revised 19 October 2011; Accepted 25 October 2011

Academic Editor: Alf Månsson

Copyright (C) 2012 Juliana De Souza Rebouças et al. This is an open access article distributed under the Creative Commons Attribution License, which permits unrestricted use, distribution, and reproduction in any medium, provided the original work is properly cited.

\begin{abstract}
In the last decades, significant progress in research and clinics has been made to offer possible innovative therapeutics for the management of allergic diseases. However, current allergen immunotherapy shows limitations concerning the long-term efficacy and safety due to local side effects and risk of anaphylaxis. Thus, effective and safe vaccines with reduced dose of allergen have been developed using adjuvants. Nevertheless, the use of adjuvants still has several disadvantages, which limits its use in human vaccines. In this context, several novel adjuvants for allergen immunotherapy are currently being investigated and developed. Currently, nanoparticles-based allergen-delivery systems have received much interest as potential adjuvants for allergen immunotherapy. It has been demonstrated that the incorporation of allergens into a delivery system plays an important role in the efficacy of allergy vaccines. Several nanoparticles-based delivery systems have been described, including biodegradable and nondegradable polymeric carriers. Therefore, this paper provides an overview of the current adjuvants used for allergen immunotherapy. Furthermore, nanoparticles-based allergen-delivery systems are focused as a novel and promising strategy for allergy vaccines.
\end{abstract}

\section{Introduction}

Over the past few years, a large increase in the prevalence of allergic diseases has been reported [1]. Epidemiological studies report that allergic sensitization is detected in more than $25 \%$ of the general population, particularly in industrialized countries [2]. Nowadays, allergy is defined as immediate reactions (also known as type I hypersensitivity) against foreign antigens, accompanied by a high IgE stimulus [3]. Various environmental proteins, namely, allergens, are recognized as foreign elements by the immune system of some individuals. Allergic diseases include rhinitis (hay fever), asthma, food allergy, allergic skin inflammation, ocular allergy, and anaphylaxis [4].

The etiology of allergic immune responses is complex, and several factors, including environmental and genetics, have been described as triggers of allergic diseases [5]. Recently, different gene polymorphisms were identified, and they also affect the individual predisposition to develop allergy, known as atopy [6-9]. However, a genetic predisposition alone does not explain the increased prevalence of these diseases in the last decades. It has been proposed that this increase seems to be attributed to environmental factors acting on a genetic basis [7].

Since the first description of allergy in early 1900s, significant progress to research and clinics has been made in offer possible innovative therapeutics for the management of allergic diseases [10-13]. Remarkable advances in allergen immunotherapy include the use of purified allergens-based vaccines [14], blocking antibodies [15], the recombinant interleukins administration [16, 17], DNA vaccines [18], and gene therapy [19]. However, current approaches show limitations concerning the long-term efficacy and safety due to local side effects and risk of anaphylaxis. Effective and safe vaccines require the use of effective and safe adjuvants [20-23]. Therefore, this paper provides an overview of 


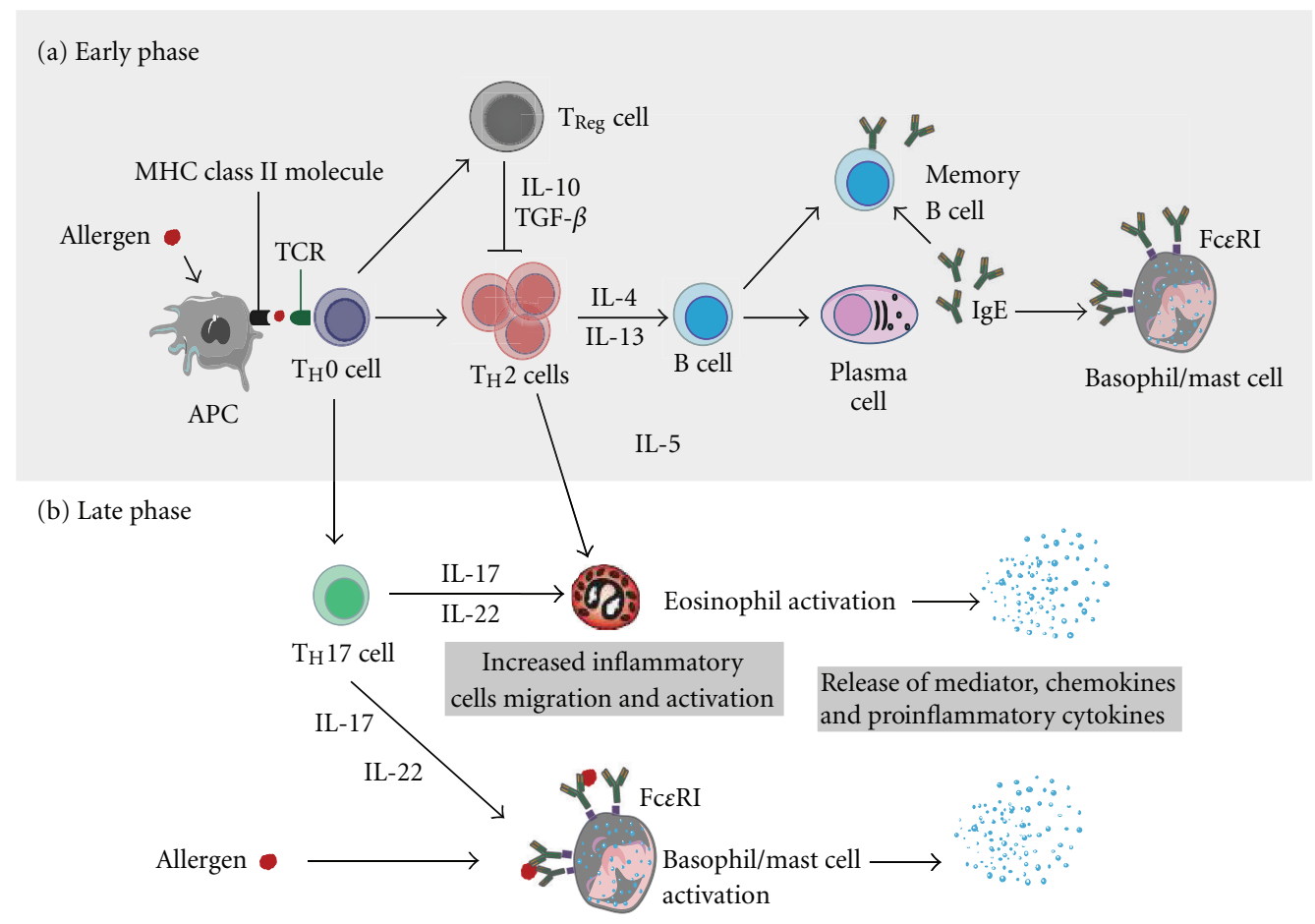

FIgURE 1: Mechanisms of allergic responses. Allergic response is constituted by two phases: an early phase (a) of initial sensitization and memory activation and a later phase response (b) after re-exposure to allergen, resulting in release of inflammatory mediators as a consequence of allergen cross-linking basophil/mast cell-bound specific IgE.

the currently adjuvants used for allergen immunotherapy. Furthermore, nanoparticles-based allergen-delivery systems are focused and discussed as a novel and promising strategy for allergy vaccines.

\section{Immunological Aspects of Allergic Diseases}

Allergic diseases are immunologic disorders characterized by an imbalance in the responses of activation of $\mathrm{CD} 4^{+} \mathrm{T}$ helper $\left(\mathrm{T}_{\mathrm{H}} 1\right.$ and $\left.\mathrm{T}_{\mathrm{H}} 2\right)$ and $\mathrm{T}$ regulatory $\left(\mathrm{T}_{\mathrm{Reg}}\right)$ cells [24]. Among the many cells involved in allergic reaction, $\mathrm{CD} 4^{+} \mathrm{T}$ cells play a central role in the immune response against allergens. In atopic individuals, functional polarization of allergenspecific response of $\mathrm{CD}^{+} \mathrm{T}$ cells and cytokine profile is $\mathrm{T}_{\mathrm{H}} 2$ polarized (Figure 1). In contrast, activated allergen-specific $\mathrm{T}$ cells from nonatopic subjects are $\mathrm{T}_{\mathrm{H}} 1$ polarized accompanied by secretion of IFN- $\gamma$ and IL-2. Allergic inflammatory cytokines are secreted, particularly IL-4, IL-5, and/or IL-13. This latter is an important mediator of allergic inflammation. IL-13 promotes immunoglobulin class switching for IgE production and increases both recruitment and activation of inflammatory cells such as eosinophils, mast cells, and basophils $[25,26]$. Recently, several studies suggest that $\mathrm{T}_{\mathrm{H}} 17$ and $\mathrm{T}_{\text {Reg }}$ also have a significant role in the development of allergic diseases $[27,28]$. Current studies have demonstrated that these novel T cells, producing IL-17 and IL-10, regulate innate immunity by signal transduction, which mitigates their proinflammatory function (Figure 1) [29].
The mechanism of the allergic reaction is characterized by two phases: the initial sensitization phase, which is followed by the second phase that is characterized by immediate hypersensitivity symptoms. After an initial exposure (Figure 1(a)), $\mathrm{T}_{\mathrm{H}} 2$ pathway is initiated by the uptake of allergens by professional antigen-presenting cells (APCs) that present peptides on MHC class II molecules to naive $\mathrm{CD}^{+} \mathrm{T}$ cells, which activate a cell response. Thereafter, high amounts of specific IgE antibodies are produced and bind to high affinity IgE receptor (FceRI) in membranes of circulating basophils and mast cells that reside in skin and mucous membranes. Upon re-exposure to the allergen (Figure 1(b)), an immediate hypersensitivity response is triggered as consequence of cross-linking of the allergen with two molecules of mast cell-bound IgE. This signal stimulates the release of histamine and other inflammatory mediators such as serine proteases, platelet activating factor, cytokines, leukotrienes and prostaglandins. These mediators increase vascular permeability and promote mucus production, which are responsible for the symptoms and signs of allergic diseases $[25,26]$.

\section{Allergen-Specific Immunotherapy}

Allergen-specific immunotherapy (SIT) involves the administration of increasing doses of allergen(s) in order to obtain a hyposensitization and long-term relief of symptoms occurring after natural allergen exposure. SIT 


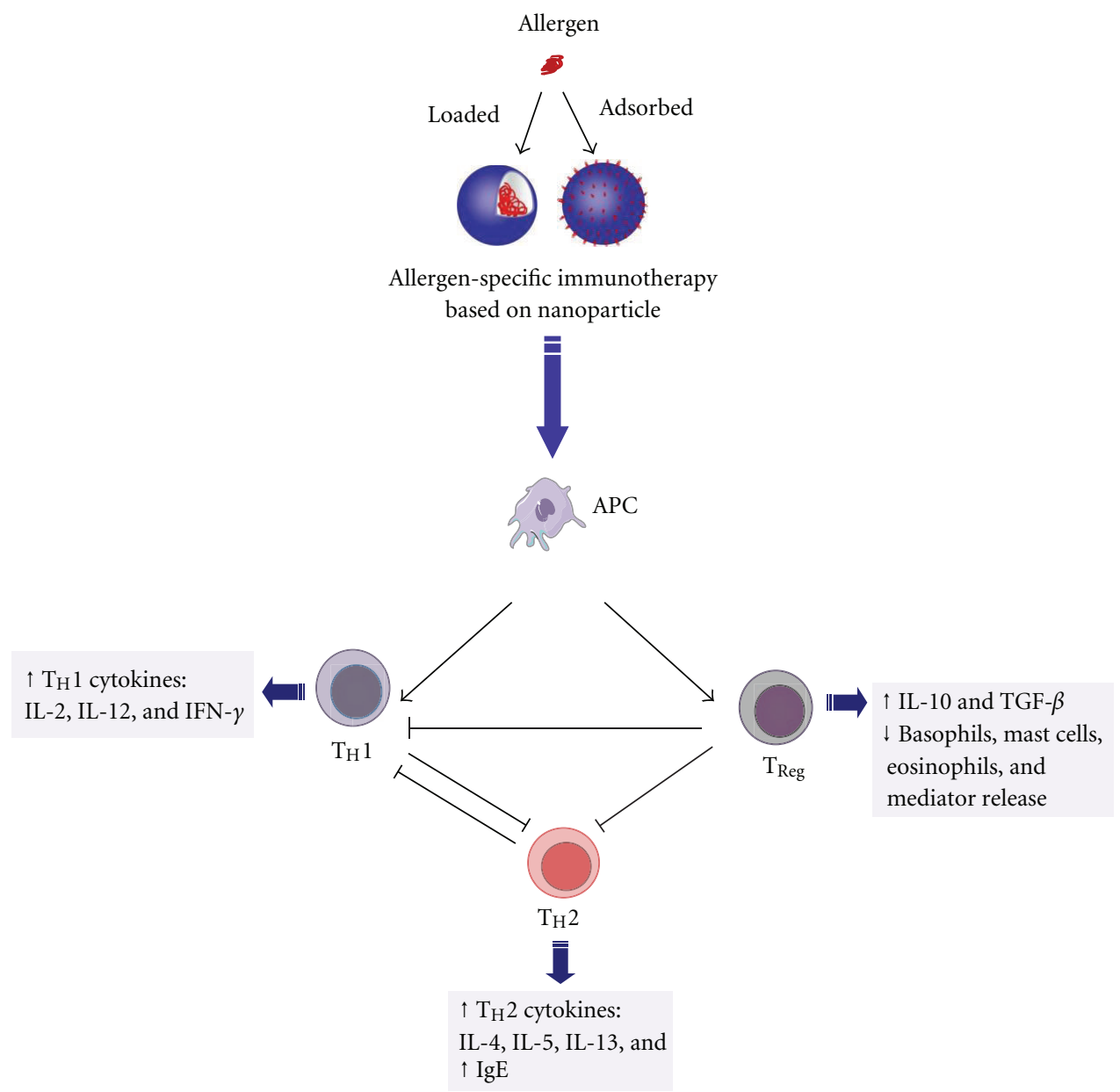

FIGURE 2: Immunomodulation of allergic diseases by using nanoparticle-based vaccines. Immunological changes after successful allergen specific-immunotherapy are indicated by whole arrows; truncated arrows indicate inhibitory effects. Redirection of allergic- $\mathrm{T}_{\mathrm{H}} 2$ responses, in favour of $\mathrm{T}$ regulatory cell induction or/and $\mathrm{T}_{\mathrm{H}} 1$ activation, are depicted.

have been considered an efficient, safe, and long-termbenefit approach, which may be combined with appropriate allergen-avoidance strategies. However, discovery of allergen-specific immunotherapy raised a number of crucial questions regarding the route of administration, the dose response relationship, and the intervals between administrations [30].

Nowadays, several immunotherapeutic strategies have been achieved to modulate the immune system by different pathways [13]. Advances in the standardization of allergenic composition of vaccines, optimal dose of allergen and, above all, clinical studies that support their effectiveness are crucial not only to achieve more effective and safe vaccines, but also to provide greater dosing convenience [31].

3.1. Mechanisms of Allergen-Specific Immunotherapy. It has been established that an immune-tolerant state represents an essential step for a successful immunotherapy [32]. Several findings suggest that SIT acts through an immunomodulatory activity (Figure 2 ), changing the $\mathrm{T}_{\mathrm{H}} 1, \mathrm{~T}_{\mathrm{H}} 2, \mathrm{~T}_{\mathrm{H}} 17$, and $\mathrm{T}_{\text {Reg }}$ cell differentiation [33-35]. Following SIT, an increase in $\mathrm{CD}^{+}$cells and $\mathrm{T}_{\mathrm{H}} 1 / \mathrm{T}_{\mathrm{H}} 0$ ratio are observed. Also, a decrease in $\mathrm{T}_{\mathrm{H}} 2 / \mathrm{T}_{\mathrm{H}} 0$ ratio takes place. Additionally, a change in cytokine response with production of IL-4 and IFN- $\gamma$ (IL-4 to IFN- $\gamma$ ) is observed as result of downregulation of $\mathrm{T}_{\mathrm{H}} 2$ or increased $\mathrm{T}_{\mathrm{H}} 1$ response. In this context, the generation of allergen-specific $\mathrm{T}_{\mathrm{Reg}}$ cells (producing IL-10 and TGF- $\beta$ ) suppressed proliferative and cytokine responses, initiating peripheral T-cell tolerance. In addition, the number of $\mathrm{T}_{\mathrm{H}} 2$ cells such as basophils and eosinophils is reduced at the allergen exposition sites (e.g., mucosa and skin), which reduces the IgE-mediated release of histamine by basophils [32-34].

Usually, SIT induces a transient increase in serum IgE, which decreases during the course of the treatment. Successful SIT is also associated with a high increase (10 to 100fold) in IgG blocking antibodies such as IgG4 and IgG1. IgG4 acts by capturing the allergen before it crosslinks with the IgE that is bound on the surface IgE receptors of mast cells and basophils, inhibiting its activation. Still, IgG4 antibodies have anti-inflammatory activity through inhibition of the production of other IgG subtypes [35]. 
Recently, the counterregulatory role of IL-10 has been demonstrated. It is secreted by $\mathrm{T}_{\text {Reg }}$ cells during SIT, which modulates isotype formation and also change the response from an IgE to an IgG4-dominated phenotype. Other indirect function of $\mathrm{T}_{\mathrm{Reg}}$ cells is the suppression of $\mathrm{T}_{\mathrm{H}} 17$ cells, accompanied by a decrease in IL-17 secretion [36].

3.2. Routes of Administration. Lately, several routes for allergen delivery have been assessed in immunotherapy. Since its discovery, the traditional SIT has been commonly given subcutaneously with high clinical efficacy [30]. However, subcutaneous immunotherapy (SCIT) is associated with a significant risk of severe adverse events $[37,38]$. Thus, efforts have been done towards alternative routes (local and noninjection) for allergen delivery [39].

In the 1980s, the sublingual route appeared as a promising noninjection route [40]. Sublingual immunotherapy (SLIT) was regarded as an efficient and safe route. Usually, SLIT is recommended for patients with severe adverse reactions to conventional SCIT [41]. Similarly, local nasal immunotherapy (LNIT) proved to be effective and safe. However, the exact mechanisms of action and optimal dose of both SLIT and LNIT has not been established yet [39]. These noninjection routes were proposed by the World Health Organization (WHO) as viable alternatives to the subcutaneous route [42]. On the other hand, clinical efficacy of oral immunotherapy (OIT) was achieved with high doses of allergen. This has induced to a major research on the development of new mucosal adjuvants, discussed in the following section.

\section{Adjuvants for Allergen Immunotherapy}

The overall goal in allergen vaccine development is improving both clinical efficacy and safety. Nevertheless, the use of high amount of allergen on allergen immunotherapy is limited by a significant risk of allergic reactions [42]. Thus, effective and safe vaccines with reduced dose of allergen have been developed using adjuvants. Adjuvants (from Latin, adjuvare, aid) are defined as heterogeneous compounds that enhance the immune response against to coadministered antigens [43].

Ideally, adjuvants for allergy immunotherapy should stimulate a $\mathrm{T}_{\mathrm{H}} 1 \mathrm{immune}$ response without inducing autoimmunity and should not be mutagenic, carcinogenic, and teratogenic. Besides, optimal adjuvants need to be apyrogenic and stable in the vaccine formulation [44]. Despite the undeniable progress in this area, the use of adjuvants still has several disadvantages, which limits its use in human vaccines. Therefore, the benefits and risks related to the use of adjuvants for allergy immunotherapy need to be counterbalanced [45]. In this context, several novel adjuvants for allergen immunotherapy are currently being investigated and developed [43].

4.1. Mechanisms of Action. Traditionally, adjuvants exert their effects in different ways: the depot effect, the targeting to antigen-presenting cells, and the nonspecific modulation of immune system [43]. The use of allergen extracts adsorbed to adjuvants protects the antigen from enzymatic degradation. On the other hand, depot formation entraps the antigen and provides its slow release. The persistence of the antigen increases the recruitment of APCs in the injection site, which triggers a prolonged inflammatory response. Then, the recruitment of competent cells activates innate and adaptive immune system.

Adjuvants can be divided into two groups according to their mechanisms of action as delivery systems and immunomodulatory adjuvants. However, some compounds can act by both mechanisms simultaneously [45-47].

4.2. Traditional Adjuvants. Hundreds of compounds and molecules have been extensively evaluated as adjuvants [45]. Aluminium salts and emulsions are traditionally used as general immunologic adjuvants. Recently, liposomes, immunostimulating complexes (ISCOMs), oligonucleotides, and microorganisms-derived adjuvants (i.e., MPL) have been introduced as novel adjuvants in allergy vaccines [44, 46-48].

4.2.1. Aluminium Hydroxide. Aluminium salts (alum) represents the most commonly used adjuvant in human vaccines. Francis and Durham showed that alum-precipitated diphtheria toxoid was more immunogenic than an aqueous toxoid [44]. Alum-adsorbed allergen extracts induce a strong $\mathrm{T}_{\mathrm{H}} 2$ response by a depot effect and also stimulates the activation of APCs, independent of Toll-like receptor (TLR) signalling, but dependent of NLR (NALP3) inflammasome [46]. Alum is the most common and safe adjuvant for injection immunotherapy in humans. However, some problems were reported after use of alum in allergic and prophylactic vaccines. These drawbacks include the enhanced sensitivity to alum and local granuloma formation at injection sites. Yet, tolerance induction has been observed after the use of aluminium. Thus, it seems to be rational to consider replacing alum compounds with other more inert molecules for the treatment of type I hypersensitivity [49].

4.2.2. Emulsions. Depot adjuvants based on Freund's adjuvants have been used in experimental studies and introduced in the clinic. Usually, the allergens are incorporated in a water-phase followed by the addition of oil and an emulsifying agent to form an emulsion. This allergen dosage forms have often a good immunogenic profile, with high efficacy, and prevented treatment-induced anaphylactic side effects. Nevertheless, frequent local reactions have limited the use of emulsions on long-term human prophylactic vaccines [46].

4.2.3. Liposomes. Liposomes are synthetic spheres based on a bilayer structure of phospholipids, which allow the encapsulation of hydrophilic antigens [50]. Liposomes act as both delivery carrier and immunomodulators. However, their low stability and manufacturing problems limited the use of these systems as adjuvants in human vaccines $[46,48]$. 
4.2.4. Monophosphoryl Lipid A. Currently, novel adjuvants derived from Gram-negative bacterial cell components have been investigated. Monophosphoryl lipid A (MPL; Coriza, USA), a purified lipopolysaccharide extracted from Salmonella minnesota, has been used as adjuvant in allergy vaccines [44]. MPL increases the activation of dentritic cells and $\mathrm{T}$ cells, inducing a shift in cytokine production with a potent $\mathrm{T}_{\mathrm{H}} 1$ response [45]. In addition, MPL has been shown to enhance both mucosal and systemic immunity after intranasal administration. Clinically, SIT with MPL has shown good efficacy and attenuated toxicity $[44,51]$.

4.2.5. ISCOMs. Immune stimulating complexes (ISCOMs) are spherical complexes of about $40 \mathrm{~nm}$, with a strong negative charge, composed of saponin, cholesterol and phospholipids. The micelles consist of three layers, hydrophilichydrophobic-hydrophilic. ISCOMs-incorporated antigens can trigger humoral, mucosal, and cellular immune responses $[48,52]$.

4.2.6. Oligonucleotides. Synthetic oligonucleotides containing immunostimulatory $\mathrm{CpG}$ (ISS) motifs present a strong induction of $\mathrm{T}_{\mathrm{H}} 1$ response. Conjugation of ISS with allergen showed enhancement in its immunogenicity and also reduced its allergenicity [53]. Moreover, it caused an increase in the activation of both dendritic and T cells, which induced a shift in cytokine production to a $\mathrm{T}_{\mathrm{H}} 1$ profile [54].

4.2.7. Particulate Delivery Systems. Particulate delivery systems belong to the category of adjuvants that facilitate the antigen uptake by APCs or by increasing the influx of professional APCs into the injection site. Among the different types of particulated delivery systems, polymer nanoparticles are a group of delivery systems with interesting abilities as adjuvants for both conventional and mucosal vaccination, since they can enhance the delivery of the loaded antigen to the gut lymphoid cells due to their ability to be captured and internalized by cells of the GALT. We will discuss in more detail the use of polymeric nanoparticles as adjuvants in the following section.

\section{Nanoparticles-Based Allergen-Delivery Systems}

Currently, nanoparticles-based allergen-delivery systems have received much interest as potential adjuvants for allergen immunotherapy [55]. It has been demonstrated that incorporation of allergens into a delivery system plays an important role in the efficacy of allergy vaccines. In the last years, several nanoparticles-based delivery systems have been described, including biodegradable and nonbiodegradable polymeric carriers $[44,45]$.

5.1. Biodegradable Polymeric Nanoparticles. Polymeric nanoparticles are colloidal carriers that vary in size from 10 to $1000 \mathrm{~nm}$ [56]. They can be divided into two categories: nanocapsules and nanospheres. Nanocapsules are vesicular systems in which the drug is confined to a cavity surrounded by a polymer membrane, whereas nanospheres are polymeric matrix in which the drug is physically and uniformly dispersed. Obtaining one or another type of nanoparticle depends on the preparation method used [57].

Over the last thirty years, different types of polymers and copolymers have been used to design nanoparticles. Among them, biodegradable polymers are the most used as great promise the field of drug-delivery systems. These types of nanoparticles provide controlled/sustained release properties, subcellular size, and biocompatibility with tissues and cells [58], and they are well established carrier systems with high potential for the delivery of bioactive macromolecules, including peptides, proteins, and nucleic acid vaccines [59]. Encapsulation in the polymers allows maintaining the integrity and activity of these biomolecules, protecting them from exposure to extreme $\mathrm{pH}$ conditions, bile and panctreatic secretions, and augments the immunopotentiating effect of the antigens [60].

It is well known that properties of nanoparticles such as size, surface charge, hydrophobicity/hydrophilicity, and steric effects of particle coating can determine its compatibility with the immune system [61-63].

Furthermore, nanoparticles can also be designed to provoke an immune response, by either direct immunostimulation of antigen presenting cells or delivering antigens to specific cellular compartments [64].

For the obtention of the desired therapeutic response, size particle control is important since microparticles are rapidly cleared by reticuloendothelial system, while nanoparticles have prolonged circulation time and are efficient drug, enzyme, and protein carriers by any route of administration $[65,66]$.

Furthermore, in order to achieve the desired therapeutic response with these biodegradable polymeric devices, it is also important, to select the right polymer to be used as an encapsulating agent, since its nature significantly influences the size and the release profile of the nanoparticles [67]. These biodegradable polymers can be either natural (chitosan, alginate, carrageenan, albumin, gelatin, collagen, among others) or synthetic [poly(lactic acids), PLA), poly(lactide-co-glycolic acids), PLGA), poly(methyl methacrylate), PMMA), poly(e-caprolactone), PCL), poly(alkylcyanoacrylates), PACA), and copolymers]. The former generally provide a relatively quick drug release, while the latter enable extended drug release over periods from days to several weeks $[67,68]$. However, the use of synthetic polymer can be limited due to the need of organic solvents and harsh formulation conditions $[58,68]$. The most commonly and extensively used polymeric nanoparticles for vaccine purposes are described in this section.

5.1.1. Polyesters. Polyesters are thermoplastic polymers with hydrolytically labile aliphatic ester linkages in their structure. Although all polyesters are theoretically degradable, only aliphatic ones with short aliphatic chains between ester bonds can degrade in the time required for most of the biomedical application [69]. These polymers are the most used biodegradable polymers as drug-delivery systems and 
have attracted considerable attention as drug carriers due to their biocompatibility and biodegradability.

(1) Polylactides. For vaccination purposes, polyesters such as PLA and PLGA (of variable MW and composition) have been the most popular materials for the preparation of polymer nanoparticles [70]. Due to its well-documented biocompatibility, safety, and biodegradability, these polymers are FDA approved for several clinical applications in humans [59].

PLGA is a polyester composed by of one or more of three different hydroxy acid monomers, d-lactic, l-lactic, and/or glycolic acids [71]. These copolymers undergo hydrolysis of its ester groups in the presence of water, and the degradation time depends on the LA:GA monomer ratio (50:50 up to 100:0), molecular mass, end functional group (free or esterified carboxylic acid), and the shape and structure of the matrix [69]. These parameters also determine the encapsulation efficiency and release rate of drugs and antigens from this material [72]. For instance, it has been demonstrated that nanoparticles prepared from a 75:25 PLGA copolymer (a slow degradation rate polymer) presented slower release rate of antigen than those prepared from a 50:50 PLGA copolymer (a fast degradation rate polymer) [73].

The application of these polymeric particles to antigen delivery has been widely investigated from the early $90 \mathrm{~s}$ [59]. Several authors have reported that due to its ability to efficiently target professional antigen presenting cells (APCs), the effects of PLGA entrapped antigen on the cellular and humoral immune response have several times been shown to be superior to application of soluble, free antigen [74-77].

Thus, both nano- and microparticles of PLGA can be used to increase and modulate immune responses against encapsulates antigens and to facilitate appropriate processing and presenting antigens to $\mathrm{T}$ cells [78-80]. Therefore, in recent years, these polymers have been studied for allergendelivery use, finding that the PLGA nanoparticles are of great interest for therapy of allergies [81-83]. As an example, PLGA nanoparticles loaded with Bet v1 (the major allergen of birch pollen) reduce the predominance of the $\mathrm{T}_{H} 2$ response, increasing the Bet v1 IgG2a levels, concomitant with an increase in IFN- $\gamma$ and IL-10 levels $[82,83]$.

Other less commonly used polylactide particles include poly(DL-lactide glycolide) or PLG microparticles that are also able to induce $\mathrm{CD}^{+} \mathrm{T}$ cell responses [84]. These particles have been used as a vehicle for Ole e 1, the main olive pollen allergen, in the desighning of allergen-specific vaccine [85].

Despite its obvious interest as nanoparticulate adjuvants and delivery systems for immunotherapy, the use of these polymers as peptide or protein delivery may negatively affect the stability of the loaded compound due to the bulk degradation mechanism of the polymer and the acidic degradation obtained products $[59,69,86-89]$. Another limitation of these nanoparticles is their insufficient stability and penetration capacity upon mucosal administration [59].

Thus, recent research has been focused on the search for additional strategies to improve the efficiency of these nanoparticles by addressing its limitations. Overall, most of these strategies involve the modification of the surface of the particles by using a suitable stabilizer. The substance most commonly used for this purpose is poly(ethylene glycol) (PEG) [59], which is a hydrophilic, non-ionic, and biocompatible polymer that can be added to the particles by different routes, including covalent bonding and mixing during nanoparticle preparation or surface adsorption [90]. For instance, it was demonstrated that PLA-PEG nanoparticles, with a high PEG coating density and small size, are significantly better transporters across the nasal mucosa than noncoated PLA and even than PLA-PEG nanoparticles with a lower coating density [91].

Different studies have been performed using these nanoparticles for vaccine purposes. For example, it has been demonstrated that recombinant hepatitis B surface antigen encapsulated within PEGylated PLGA nanoparticles allows generating very fast immune responses compared to the non encapsulated antigen counterpart [92]. Other authors achieved an enhancement of the transport of the PEG-PLA nanoparticles encapsulated tetanus toxin across the intestinal barrier $[93,94]$.

(2) Poly( $\varepsilon$-Caprolactone). Poly( $\varepsilon$-caprolactone) (PCL) is a biocompatible, bioerodable, biodegradable and semicrystalline polyester that can be used for the formulation of nanoparticles [68]. Due to the semicrystallinity and hydrophobicity, the in vivo degradation of PCL is much slower than PLGA, making it more appropriate for longterm delivery systems, extending over a period of more than one year $[58,95]$. Furthermore, PCL particles, unlike polylactides, do not generate an acidic environment that could negatively affect the antigenicity of the encapsulated antigens or allergens [96].

However, most of the PCL studies found in the field of immunotherapy have been performed using PCL microparticles/microspheres [95]. Studies that use this polymer as nanoparticles for allergen immunotherapy have not been found and it has been little used as nanoparticulate adjuvant system for vaccine development. For example, PCL nanospheres together with mucoadhesive polymers (alginate or chitosan) were used as a potential carrier for Streptococcus equi surface proteins. Serum IgG antibody levels of animals vaccinated with $S$. equi antigens encapsulated or adsorbed onto PCL particles were significantly higher than those caused by free antigens or even free antigens adjuvanted with cholera toxin B subunit [97]. Thus, although no examples of the use of PCL nanoparticles for allergen immunotherapy were found, the good results obtained by different authors by using these PCL-nanoparticles in the field of vaccination suggest these systems as potential adjuvants in allergen immunotherapy.

5.1.2. Poly(Anhydrides). In contrast to polylactide nanoparticles, the degradation products of polyanhydrides are noncytotoxic and less acidic than those of polyesters, which can improve the stability of encapsulated antigen [88]. The copolymers between methyl vinyl ether and maleic 
anhydride (PVMA) (commercialized as Gantrez AN from ISP, Corp.) are a good example of these polyanhydrides. Due to the presence of reactive anhydride groups which do not need time-consuming chemical activation, this copolymer allows to easily prepare nanoparticles under mild conditions, using a solvent displacement method [98]. Moreover, a recent research concluded that the use of Gantrez AN 119 nanoparticles prepared by using reduced amount of organic solvent (acetone) facilitates the encapsulation of the antigen and offers a mild irritation at mucosal epithelia when orally unstabilised nanoparticles are used [99].

One of the most important properties of the Gantrez nanoparticles is their ability to develop strong bioadhesive interactions with components of the gut mucosa [100]. In addition, their surface can be easily modified by simple incubation with different excipients or ligands in order to modify their in vivo distribution [101, 102], and even to increase its affinity for the intestinal mucosa [100]. This makes Gantrez nanoparticles good candidates for oral immunotherapy treatments, which have many evident advantages (patient compliance, safest route, least expensive route etc). In fact, some studies have demonstrated the efficacy of these particles by this route. For example, Gómez and coworkers [103] found enhancements in both $\mathrm{T}_{\mathrm{H}} 1$ and $\mathrm{T}_{\mathrm{H}} 2$ markers (IgG2a and IgG1, resp.) after oral administration Gantrez AN nanoparticles loaded with ovalbumin as allergen model. Moreover, these carriers were able to protect a model of sensitized mice to ovalbumin from anaphylactic shock. Thus, these PVMA nanoparticles have been widely used as carriers for controlled delivery of antigens such as Lolium perenne (allergenic proteins of rye-grass pollen) $(\mathrm{N}),[88,103-106]$.

Another advantage of this copolymer is that it can easily react with amino groups, which makes easy to load or link different types of immunostimulants, like proteins or even lipopolysaccharides.

Also, the loading of antigens into these bioadhesive nanoparticles has demonstrated to enhance the immune responses in terms of a potent $\mathrm{T}_{\mathrm{H}} 1$ adjuvant capacity $[103,105,107]$. This strong response may be due to the effect produced by the nanoparticles that promote close interactions between antigen and antigen-presenting cells, and also act as agonists of various Toll-like receptors (TLRs), mainly TLR2 and TLR $4[86,108]$.

Other polyanhydrides based on hydrophobic moieties or on oligomeric ethylene glycol-containing anhydrides have been shown promise as novel vaccine carriers with immunomodulatory capabilities [88].

5.1.3. Poly (Gamma-Glutamic Acid). Poly(gamma-glutamic acid) $(\gamma$-PGA) is a high molecular weight polypeptide composed of $\gamma$-linked glutamic acid units and $\alpha$-carboxylate side chains produced by certain strains of Bacillus [109]. Due to the amphiphilic nature of the hydrophobically modified $\gamma$-PGA copolymer, it is possible to form nanoparticles with a simple methodology [110]. In recent years, a research group has developed biodegradable nanoparticles using $\gamma$ PGA with L-phenylalanine ethyl ester and evaluated the feasibility of protein entrapment on/into this carriers as well as their biological potential. As a result of these rechearches, ovalbumin (OVA), as a model protein, was successfully encapsulated in these nanoparticles, which also did not induce any cytotoxicity against HL-60 cells [109].

Subsequent studies also showed that these particles are activators of human monocyte-derived dendritic cells and strongly stimulate the production of chemokines and inflammatory cytokines as well as upregulation of costimulatory molecules and immunomodulatory mediators involved in efficient $\mathrm{T}$ cell priming. Furthermore, in vitro studies with monocyte-derived dendritic cells and grass pollen allergen Phleum pratense loaded $\gamma$-PGA nanoparticles showed an increase allergen-specific IL-10 production and proliferation of autologous $\mathrm{CD}^{+}$memory T cells [110].

Additionally, studies show that these biodegradable nanoparticles induce in vitro innate immune cell activation, produce antigen-specific immune responses in vivo through the TLR 4 and MyD88-dependent signaling pathway, and can influence innate and adaptive immune responses by first-line host sensor [111].

In conclusion, these systems seem to be a new and good adjuvants and antigen carriers for allergen-specific immunotherapy.

5.1.4. Poly(Vinylpyrrolidone). Although fewer employees than polymers described before, there are some studies that suggest the interest of using poly(vinylpyrrolidone) (PVP) for the obtention of promising allergen-delivery nanocarriers. For example, Madan and coworkers [112] showed a successful entrapment of antigens of Aspergillus fumigatus (pathogenic fungi responsible of several allergic diseases) and found a sustained IgG antibody levels for approximately 12 weeks in comparison to IgG levels for 7 days with free antigen after immunization of male $\mathrm{BALB} / \mathrm{c}$ mice. Moreover, $\mathrm{IgE}$ levels of allergens loaded PVP nanoparticles were lower than observed in free allergens studies.

5.1.5. Polysaccharides. The most investigated polysaccharide for mucosal vaccine delivery is chitosan, poly(D-glucosamine). This polymer is prepared by the partial Ndeacetylation of chitin, a natural polymer, the second most abundant natural polysaccharide in nature, which is derived from the cuticles of insect species or crustaceans such as crabs and shrimp [113].

Chitosan is soluble in weekly acid solutions, resulting in the formation of a cationic polymer with high charge density, and can therefore form polyelectrolyte complexes with a large variety of anionic polymers [69]. Besides, due to the presence of highly reactive amino groups along its structure, chitosan is susceptible to chemical or biological functionalization [114]. Also, the preparation of chitosan nanoparticles based on the basis this polymer can be easily done without the use of organic solvents, which is interesting to maintain the immunogenicity of the antigens [115].

Chitosan possesses other advantageous properties such as low production costs, biocompatibility, biodegradability, and nontoxicity that, along with its ability to enhance the penetration of macromolecules across the intestinal and 
nasal barriers, make it a suitable candidate for the design of mucosal vaccine formulations [68, 69, 116-119]. Thus, slowed mucociliary transport as well as a transient increase in paracellular absorption should lead to an improved immunological response [115].

Several studies have reported the use of chitosanbased nanocarriers for gene delivery [120-122]. CS-based nanocomplexes have been developed for the targeted delivery of plasmid DNA (pDNA) and also as carriers for RNA [122, 123].

Chitosan nanoparticles incorporating soluble antigens as diphtheria and tetanus toxoids and plasmid DNA induced high and long-lasting IgG immune responses, demonstrating the effectiveness of these devices for intranasal vaccination $[93,124]$. This significant systemic and mucosal immune response enhancement after nasally administered chitosan nanoparticles has been demonstrated also for influenza, pertussis, and diphtheria vaccines $[115,124]$. However, until now, the mechanism by which the antigen is delivered to the nasal mucosa and the role of the physicochemical characteristics of the particles in this processes have not been well determined, and there is some contradictory theories [124].

For oral vaccination studies, Roy and coworkers have demonstrated the effectiveness of orally delivered chitosanDNA nanoparticles in inducing protective immunity in the peanut allergy mouse model [125]. More specifically, chitosan nanoparticles loaded with the gene for Ara h2 (main peanut allergen) allow to obtain a significant reduction in the levels of serum IgE, plasma histamine, and vascular leakage and the induction of specific mucosal IgA antibodies.

Other studies show a significant amelioration of ovalbumin-induced food allergy symptoms when the TGFbeta expressing DNA vector is orally administered after its encapsulation in chitosan nanoparticles, compared to the previously reported protein-based strategies [126].

However, in spite of all the described advantageous properties of chitosan, this polymer has a major limitation: its low solubility at physiological $\mathrm{pH}$ and therefore loses of its ability to enhance drug permeability and absorption [127, 128].

To improve this drawback, several derivatives of chitosan have been studied, such as trimethyl chitosan (TMC), that shows high solubility, bioadhesive properties, and ability to enhance permeability over a wide $\mathrm{pH}$ range $[129,130]$. In fact, a recent study shows that trimethylated chitosan nanoparticles obtained by using a new mild method induced stronger humoral and mucosal immune responses compared to generate by chitosan conventional nanoparticles [131].

Other interesting alternative is the use of chitosan together with other biodegradable polyelectrolyte polymers with opposite charge to obtain combined nanoparticles suitable for mucosal vaccinations. A typical example of this second polymer can be sodium alginate, another biodegradable and biocompatible polysaccharide. For instance, it has been demonstrated that alginate-chitosan-coated nanoparticles are an effective system for subcutaneous and oral vaccination with the recombinant hepatitis B surface antigen [132-134]. Another study shows that these nanoparticles can prevent a burst release of loaded ovalbumin and improve its stability in simulated intestinal fluid at $37^{\circ} \mathrm{C}$ [132].

5.2. Nondegradable Polymeric Nanoparticles. Nondegradable nanoparticles of different materials such as latex, gold, silica, or polystyrene are being evaluated as antigen carriers for induction of immunity $[70,77,135]$. It is considered that by using these particles, the antigen can be presented to the immune system for extended periods of time, and thus improve the immunogenicity, probably due to the persistence of the nanoparticles in the tissues [70,77].

On the other hand, these polymers have several technological advantages [64]. For example, polystyrene nanoparticles can be made with several functional groups on their surface to achieve effective conjugation with a variety of antigens. Furthermore, when the antigen is covalently coupled to the particle, it induces higher cellular and humoral responses than in the cases where the antigen is absorbed [136].

For latex particles, some examples in the literature have demonstrated that this polymer was presented 100010,000-fold more efficiently by MHC-Class I molecules than soluble antigens [137] or antigens presented via MHCClass II molecules [138]. Gold nanoparticles also appear to enhance the effect of DNA vaccination by improving delivery onto cellular interiors [139]. However, these results are obtained using electroporation, which may not be applicable in humans due to cell mortality. In the absence of this technique, so by passive diffusion, the immunological effects were not so interesting [140]. Other recent studies show that the use of gold nanoparticles along with alum can enhance the immune response against PfMSP-119 and PvMSP-119 [141].

However, in general terms, it was shown that nondegradable particles were much less effective at cross-presenting antigens than degradable ones [142, 143]. Also, to use this type of nanoparticles for vaccination purposes is necessary to consider aspects of toxicity and particles aggregation in the tissues, which requires follow-up studies of in vivo clearance and the determination of possible adverse effects resulting from its use [77].

\section{Conclusion}

In summary, the use of nanotechnology platforms, although widespread in recent years for vaccination purposes [98, 106], is emerging in the field of allergen immunotherapy [103-105]. Given the promising results obtained so far, polymeric nanoparticles can be of interest to develop new therapeutic strategies able to improve both clinical efficacy and safety of allergen vaccines.

On the other hand, our knowledge of the nanoparticle interaction with the immune system has been increased in recent years, but it still remains insufficient. Thus, further studies related to the immunomodulatory effects of the polymeric nanoparticles are required to improve our understanding, and therefore our capability, to design better specific and effective allergen vaccines. 


\section{Funding}

This research was financially supported by Health Department of "Gobierno de Navarra" (Grant no. 28/2007), "Instituto de Salud Carlos III" (Grant no. PS09/01083), and "Fundación Ramón Areces". J. D. S. Rebouças was also financially supported by "Asociación de Amigos", University of Navarra, Spain. M. Ferrer and M. L. Sanz and M.B. are supported by grant RD07/0064 from the Spanish Research Network on Adverse Reactions to Allergens and Drugs (RIRAAF: Red de Investigación de Reacciones Adversas a Alérgenos y Fármacos) of the Carlos III Health Institute.

\section{References}

[1] D. J. Martino and S. L. Prescott, "Silent mysteries: epigenetic paradigms could hold the key to conquering the epidemic of allergy and immune disease," Allergy, vol. 65, no. 1, pp. 7-15, 2010.

[2] S. H. Sicherer and H. A. Sampson, "Peanut allergy: emerging concepts and approaches for an apparent epidemic," Journal of Allergy and Clinical Immunology, vol. 120, no. 3, pp. 491503, 2007.

[3] P. G. H. Gell and R. R. A. Coombs, Clinical Aspects of Immunology, Blackwell, Oxford, UK, 1st edition, 1963.

[4] J. O. Warner, M. A. Kaliner, C. D. Crisci et al., "Allergy practice worldwide: a report by the World Allergy Organization Specialty and Training Council," International Archives of Allergy and Immunology, vol. 139, no. 2, pp. 166-174, 2006.

[5] A. P. Grammatikos, "The genetic and environmental basis of atopic diseases," Annals of Medicine, vol. 40, no. 7, pp. 482495, 2008.

[6] D. Vercelli, "Discovering susceptibility genes for asthma and allergy," Nature Reviews Immunology, vol. 8, no. 3, pp. 169$182,2008$.

[7] C. Ober, S. A. Leavitt, A. Tsalenko et al., "Variation in the interleukin 4-receptor $\alpha$ gene confers susceptibility to asthma and atopy in ethnically diverse populations," American Journal of Human Genetics, vol. 66, no. 2, pp. 517-526, 2000.

[8] G. M. Hunninghake, M. E. Soto-Quirós, L. Avila et al., "Polymorphisms in IL13, total IgE, eosinophilia, and asthma exacerbations in childhood," Journal of Allergy and Clinical Immunology, vol. 120, no. 1, pp. 84-90, 2007.

[9] X. Liu, T. H. Beaty, P. Deindl et al., "Associations between specific serum IgE response and 6 variants within the genes IL4, IL13, and IL4RA in German children: the German Multicenter Atopy Study," Journal of Allergy and Clinical Immunology, vol. 113, no. 3, pp. 489-495, 2004.

[10] L. O'Mahony, M. Akdis, R. Crameri, and C. A. Akdis, "Novel immunotherapeutic approaches for allergy and asthma," Autoimmunity, vol. 43, no. 7, pp. 493-503, 2010.

[11] N. Novak, "New insights into the mechanism and management of allergic diseases: atopic dermatitis," Allergy, vol. 64, no. 2, pp. 265-275, 2009.

[12] V. Niederberger and R. Valenta, "Molecular approaches for new vaccines against allergy," Expert Review of Vaccines, vol. 5, no. 1, pp. 103-110, 2006.

[13] J. M. Rolland, L. M. Gardner, and R. E. O’Hehir, "Allergenrelated approaches to immunotherapy," Pharmacology and Therapeutics, vol. 121, no. 3, pp. 273-284, 2009.

[14] G. Pauli and H. J. Malling, "The current state of recombinant allergens for immunotherapy," Current Opinion in Allergy and Clinical Immunology, vol. 10, no. 6, pp. 575-581, 2010.
[15] R. T. Strait, S. C. Morris, and F. D. Finkelman, "IgG-blocking antibodies inhibit IgE-mediated anaphylaxis in vivo through both antigen interception and Fc $\gamma$ RIIb cross-linking," The Journal of Clinical Investigation, vol. 116, no. 3, pp. 833-841, 2006.

[16] Y. Ma, K. T. Hayglass, A. B. Becker et al., "Novel cytokine peptide-based vaccines: an interleukin-4 vaccine suppresses airway allergic responses in mice," Allergy, vol. 62, no. 6, pp. 675-682, 2007.

[17] Y. Ma, K. T. HayGlass, A. B. Becker et al., "Novel recombinant interleukin-13 peptide-based vaccine reduces airway allergic inflammatory responses in mice," American Journal of Respiratory and Critical Care Medicine, vol. 176, no. 5, pp. 439445, 2007.

[18] P. Pulsawat, S. Piboonpocanun, S. Sirivichayakul et al., "Production and immunogenicity of hypoallergenic codonoptimized DNA vaccine encoding mature Der p 1 allergen," Journal of Investigational Allergology and Clinical Immunology, vol. 20, no. 7, pp. 582-590, 2010.

[19] G. K. Gupta and D. K. Agrawal, "CpG oligodeoxynucleotides as TLR9 agonists: therapeutic application in allergy and asthma," BioDrugs, vol. 24, no. 4, pp. 225-235, 2010.

[20] D. I. Bernstein, T. Epstein, K. Murphy-Berendts, and G. M. Liss, "Surveillance of systemic reactions to subcutaneous immunotherapy injections: year 1 outcomes of the ACAAI and AAAAI Collaborative Study," Annals of Allergy, Asthma and Immunology, vol. 104, no. 6, pp. 530-535, 2010.

[21] S. Broos, K. Lundberg, T. Akagi et al., "Immunomodulatory nanoparticles as adjuvants and allergen-delivery system to human dendritic cells: implications for specific immunotherapy," Vaccine, vol. 28, no. 31, pp. 5075-5085, 2010.

[22] R. Klippstein and D. Pozo, "Nanotechnology-based manipulation of dendritic cells for enhanced immunotherapy strategies," Nanomedicine, vol. 6, no. 4, pp. 523-529, 2010.

[23] I. Schöll, G. Boltz-Nitulescu, and E. Jensen-Jarolim, "Review of novel particulate antigen delivery systems with special focus on treatment of type I allergy," Journal of Controlled Release, vol. 104, no. 1, pp. 1-27, 2005.

[24] S. Romagnani, "Immunologic influences on allergy and the TH1/TH2 balance," Journal of Allergy and Clinical Immunology, vol. 113, no. 3, pp. 395-400, 2004.

[25] D. S. Robinson, "Th-2 cytokines in allergic disease," British Medical Bulletin, vol. 56, no. 4, pp. 956-968, 2000.

[26] M. I. Araujo, R. A. Campos, L. S. Cardoso, S. C. Oliveira, and E. M. Carvalho, "Immunomodulation of the allergic inflammatory response: new developments," Inflammation and Allergy-Drug Targets, vol. 9, no. 2, pp. 73-82, 2010.

[27] Y. Zhao, J. Yang, and Y.-D. Gao, "Altered expressions of helper T cell (Th)1, Th2, and Th17 cytokines in CD8+ and $\gamma \delta$ T cells in patients with allergic asthma," Journal of Asthma, vol. 48, no. 5, pp. 429-436, 2011.

[28] O. Palomares, G. Yaman, A. K. Azkur, T. Akkoc, M. Akdis, and C. A. Akdis, "Role of Treg in immune regulation of allergic diseases," European Journal of Immunology, vol. 40, no. 5, pp. 1232-1240, 2010.

[29] K. Oboki, T. Ohno, H. Saito, and S. Nakae, "Th17 and allergy," Allergology International, vol. 57, no. 2, pp. 121-134, 2008.

[30] A. J. Frew, "Allergen immunotherapy," Journal of Allergy and Clinical Immunology, vol. 125, no. 2, pp. S306-S313, 2010.

[31] R. Valenta and D. Kraft, "From allergen structure to new forms of allergen-specific immunotherapy," Current Opinion in Immunology, vol. 14, no. 6, pp. 718-727, 2002. 
[32] S. J. Till, J. N. Francis, K. Nouri-Aria, and S. R. Durham, "Mechanisms of immunotherapy," Journal of Allergy and Clinical Immunology, vol. 113, no. 6, pp. 1025-1034, 2004.

[33] M. Larché, C. A. Akdis, and R. Valenta, "Immunological mechanisms of allergen-specific immunotherapy," Nature Reviews Immunology, vol. 6, no. 10, pp. 761-771, 2006.

[34] G. Ciprandi, G. L. Marseglia, and M. A. Tosca, "Allergenspecific immunotherapy: an update on immunological mechanisms of action," Monaldi Archives for Chest Disease, vol. 65, no. 1, pp. 34-37, 2006.

[35] C. A. Akdis and M. Akdis, "Mechanisms and treatment of allergic disease in the big picture of regulatory T cells," Journal of Allergy and Clinical Immunology, vol. 123, no. 4, pp. 735-746, 2009.

[36] M. Akdis and C. A. Akdis, "Therapeutic manipulation of immune tolerance in allergic disease," Nature Reviews Drug Discovery, vol. 8, no. 8, pp. 645-660, 2009.

[37] D. I. Bernstein, T. Epstein, K. Murphy-Berendts, and G. M. Liss, "Surveillance of systemic reactions to subcutaneous immunotherapy injections: year 1 outcomes of the ACAAI and AAAAI Collaborative Study," Annals of Allergy, Asthma and Immunology, vol. 104, no. 6, pp. 530-535, 2010.

[38] S. R. Roy, J. R. Sigmon, J. Olivier, J. E. Moffitt, D. A. Brown, and G. D. Marshall, "Increased frequency of large local reactions among systemic reactors during subcutaneous allergen immunotherapy," Annals of Allergy, Asthma and Immunology, vol. 99, no. 1, pp. 82-86, 2007.

[39] G. W. Canonica and G. Passalacqua, "Noninjection routes for immunotherapy," Journal of Allergy and Clinical Immunology, vol. 111, no. 3, pp. 437-448, 2003.

[40] C. Ozdemir, "An immunological overview of allergen specific immunotherapy—subcutaneous and sublingual routes," Therapeutic Advances in Respiratory Disease, vol. 3, no. 5, pp. 253-262, 2009.

[41] G. W. Canonica, J. Bousquet, T. Casale et al., "Sub-lingual immunotherapy: world allergy organization position paper 2009," Allergy, vol. 64, no. 91, pp. 1-59, 2009.

[42] J. Bousquet, R. Lockey, H. J. Malling et al., "Allergen immunotherapy: therapeutic vaccines for allergic diseasesa WHO position paper," Journal of Allergy and Clinical Immunology, vol. 102, no. 4, pp. 558-562, 1998.

[43] W. Wang and M. Singh, "Selection of adjuvants for enhanced vaccine potency," World Journal of Vaccines, vol. 1, pp. 33-78, 2011.

[44] J. N. Francis and S. R. Durham, "Adjuvants for allergen immunotherapy: experimental results and clinical perspectives," Current Opinion in Allergy and Clinical Immunology, vol. 4, no. 6, pp. 543-548, 2004.

[45] A. W. Wheeler and S. R. Woroniecki, "Immunological adjuvants in allergy vaccines: past, present and future," Allergology International, vol. 50, no. 4, pp. 295-301, 2001.

[46] J. C. Aguilar and E. G. Rodríguez, "Vaccine adjuvants revisited," Vaccine, vol. 25, no. 19, pp. 3752-3762, 2007.

[47] Y. Perrie, A. R. Mohammed, D. J. Kirby, S. E. McNeil, and V. W. Bramwell, "Vaccine adjuvant systems: enhancing the efficacy of sub-unit protein antigens," International Journal of Pharmaceutics, vol. 364, no. 2, pp. 272-280, 2008.

[48] A. des Rieux, V. Fievez, M. Garinot, Y. J. Schneider, and V. Préat, "Nanoparticles as potential oral delivery systems of proteins and vaccines: a mechanistic approach," Journal of Controlled Release, vol. 116, no. 1, pp. 1-27, 2006.

[49] R. K. Gupta, "Aluminum compounds as vaccine adjuvants," Advanced Drug Delivery Reviews, vol. 32, no. 3, pp. 155-172, 1998.
[50] A. C. Allison and G. Gregoriadis, "Liposomes as immunological adjuvants," Nature, vol. 252, no. 5480, article 252, 1974.

[51] G. De Becker, V. Moulin, B. Pajak et al., "The adjuvant monophosphoryl lipid A increases the function of antigenpresenting cells," International Immunology, vol. 12, no. 6, pp. 807-815, 2000.

[52] I. Schöll, G. Boltz-Nitulescu, and E. Jensen-Jarolim, "Review of novel particulate antigen delivery systems with special focus on treatment of type I allergy," Journal of Controlled Release, vol. 104, no. 1, pp. 1-27, 2005.

[53] H. Tighe, K. Takabayashi, D. Schwartz et al., "Conjugation of immunostimulatory DNA to the short ragweed allergen Amb a 1 enhances its immunogenicity and reduces its allergenicity," Journal of Allergy and Clinical Immunology, vol. 106, no. 1, pp. 124-134, 2000.

[54] M. K. Tulic, P. O. Fiset, P. Christodoulopoulos et al., "Amb a 1-immunostimulatory oligodeoxynucleotide conjugate immunotherapy decreases the nasal inflammatory response," Journal of Allergy and Clinical Immunology, vol. 113, no. 2, pp. 235-241, 2004.

[55] S. Broos, K. Lundberg, T. Akagi et al., "Immunomodulatory nanoparticles as adjuvants and allergen-delivery system to human dendritic cells: implications for specific immunotherapy," Vaccine, vol. 28, no. 31, pp. 5075-5085, 2010.

[56] J. Kreuter, "Nanoparticles," in Encyclopaedia of Pharmaceutical Technology, J. Swarbrick and J. C. Boylan, Eds., vol. 10, pp. 165-190, Marcel Dekker, New York, NY, USA, 1994.

[57] P. Couvreur, G. Barratt, E. Fattal, P. Legrand, and C. Vauthier, "Nanocapsule technology: a review," Critical Reviews in Therapeutic Drug Carrier Systems, vol. 19, no. 2, pp. 99-134, 2002.

[58] A. Kumari, S. K. Yadav, and S. C. Yadav, "Biodegradable polymeric nanoparticles based drug delivery systems," Colloids and Surfaces B, vol. 75, no. 1, pp. 1-18, 2010.

[59] N. Csaba, M. Garcia-Fuentes, and M. J. Alonso, "Nanoparticles for nasal vaccination," Advanced Drug Delivery Reviews, vol. 61, no. 2, pp. 140-157, 2009.

[60] T. Madan, N. Munshi, T. K. De, A. Maitra, P. Usha Sarma, and S. S. Aggarwal, "Biodegradable nanoparticles as a sustained release system for the antigens/allergens of Aspergillus fumigatus: preparation and characterisation," International Journal of Pharmaceutics, vol. 159, no. 2, pp. 135-147, 1997.

[61] P. Aggarwal, J. B. Hall, C. B. McLeland, M. A. Dobrovolskaia, and S. E. McNeil, "Nanoparticle interaction with plasma proteins as it relates to particle biodistribution, biocompatibility and therapeutic efficacy," Advanced Drug Delivery Reviews, vol. 61, no. 6, pp. 428-437, 2009.

[62] M. A. Dobrovolskaia, P. Aggarwal, J. B. Hall, and S. E. McNeil, "Preclinical studies to understand nanoparticle interaction with the immune system and its potential effects on nanoparticle biodistribution," Molecular Pharmaceutics, vol. 5, no. 4, pp. 487-495, 2008.

[63] M. A. Dobrovolskaia and S. E. McNeil, "Immunological properties of engineered nanomaterials," Nature Nanotechnology, vol. 2, no. 8, pp. 469-478, 2007.

[64] M. Kalkanidis, G. A. Pietersz, S. D. Xiang et al., "Methods for nano-particle based vaccine formulation and evaluation of their immunogenicity," Methods, vol. 40, no. 1, pp. 20-29, 2006.

[65] J. C. Gautier, J. L. Grangier, A. Barbier et al., "Biodegradable nanoparticles for subcutaneous administration of growth hormone releasing factor (hGRF)," Journal of Controlled Release, vol. 20, no. 1, pp. 67-77, 1992. 
[66] P. Couvreur et al., "Biodegradable polymeric nanoparticles as drug carrier for antitumor agents," in Polymeric Nanoparticles and Microspheres, P. Guiot and P. Couvreur, Eds., pp. 27-93, CRC Press, Boca Raton, Fla, USA, 1986.

[67] V. W. Bramwell and Y. Perrie, "Particulate delivery systems for vaccines: what can we expect?" Journal of Pharmacy and Pharmacology, vol. 58, no. 6, pp. 717-728, 2006.

[68] J. M. Irache, I. Esparza, C. Gamazo, M. Agüeros, and S. Espuelas, "Nanomedicine: novel approaches in human and veterinary therapeutics," Veterinary Parasitology, vol. 180, no. 1-2, pp. 47-71, 2011.

[69] K. S. Soppimath, T. M. Aminabhavi, A. R. Kulkarni, and W. E. Rudzinski, "Biodegradable polymeric nanoparticles as drug delivery devices," Journal of Controlled Release, vol. 70, no. 12, pp. 1-20, 2001.

[70] L. J. Peek, C. R. Middaugh, and C. Berkland, "Nanotechnology in vaccine delivery," Advanced Drug Delivery Reviews, vol. 60, no. 8, pp. 915-928, 2008.

[71] R. C. Mundargi, V. R. Babu, V. Rangaswamy, P. Patel, and T. M. Aminabhavi, "Nano/micro technologies for delivering macromolecular therapeutics using poly(d,1-lactide-coglycolide) and its derivatives," Journal of Controlled Release, vol. 125, no. 3, pp. 193-209, 2008.

[72] H. Tamber, P. Johansen, H. P. Merkle, and B. Gander, "Formulation aspects of biodegradable polymeric microspheres for antigen delivery," Advanced Drug Delivery Reviews, vol. 57, no. 3, pp. 357-376, 2005.

[73] A. G. A. Coombes, E. C. Lavelle, P. G. Jenkins, and S. S. Davis, "Single dose, polymeric, microparticle-based vaccines: the influence of formulation conditions on the magnitude and duration of the immune response to a protein antigen," Vaccine, vol. 14, no. 15, pp. 1429-1438, 1996.

[74] I. D. Spiers, J. E. Eyles, L. W. J. Baillie, E. D. Williamson, and H. O. Alpar, "Biodegradable microparticles with different release profiles: effect on the immune response after a single administration via intranasal and intramuscular routes," Journal of Pharmacy and Pharmacology, vol. 52, no. 10, pp. 1195-1201, 2000.

[75] M. Igartua, R. M. Hernández, A. Esquisabel, A. R. Gascón, M. B. Calvo, and J. L. Pedraz, "Enhanced immune response after subcutaneous and oral immunization with biodegradable PLGA microspheres," Journal of Controlled Release, vol. 56, no. 1-3, pp. 63-73, 1998.

[76] J. H. Eldrige, J. K. Staas, J. A. Meulbroek, J. R. McGhee, T. R. Tice, and R. M. Gilley, "Biodegradable microspheres as a vaccine delivery system," Molecular Immunology, vol. 28, no. 3, pp. 287-294, 1991.

[77] B. Combadière and B. Mahé, "Particle-based vaccines for transcutaneous vaccination," Comparative Immunology, Microbiology and Infectious Diseases, vol. 31, no. 2-3, pp. 293 315, 2008.

[78] H. Sun, K. G. J. Pollock, and J. M. Brewer, "Analysis of the role of vaccine adjuvants in modulating dendritic cell activation and antigen presentation in vitro," Vaccine, vol. 21, no. 9-10, pp. 849-855, 2003.

[79] C. Clawson, C. T. Huang, D. Futalan et al., "Delivery of a peptide via poly(d,l-lactic-co-glycolic) acid nanoparticles enhances its dendritic cell-stimulatory capacity," Nanomedicine, vol. 6, no. 5, pp. 651-661, 2010.

[80] C. S. W. Chong, M. Cao, W. W. Wong et al., "Enhancement of $\mathrm{T}$ helper type 1 immune responses against hepatitis $\mathrm{B}$ virus core antigen by PLGA nanoparticle vaccine delivery," Journal of Controlled Release, vol. 102, no. 1, pp. 85-99, 2005.
[81] I. Schöll, G. Boltz-Nitulescu, and E. Jensen-Jarolim, "Review of novel particulate antigen delivery systems with special focus on treatment of type I allergy," Journal of Controlled Release, vol. 104, no. 1, pp. 1-27, 2005.

[82] I. Schöll, T. Kopp, B. Bohle, and E. Jensen-Jarolim, "Biodegradable PLGA particles for improved systemic and mucosal treatment of Type I allergy," Immunology and Allergy Clinics of North America, vol. 26, no. 2, pp. 349-364, 2006.

[83] I. Schöll, A. Weissenböck, E. Förster-Waldl et al., "Allergenloaded biodegradable poly(D,L-lactic-co-glycolic) acid nanoparticles down-regulate an ongoing Th2 response in the BALB/c mouse model," Clinical and Experimental Allergy, vol. 34, no. 2, pp. 315-321, 2004.

[84] C. D. Partidos, P. Vohra, D. H. Jones, G. Farrar, and M. W. Steward, "Induction of cytotoxic T-cell responses following oral immunization with synthetic peptides encapsulated in PLG microparticles," Journal of Controlled Release, vol. 62, no. 3, pp. 325-332, 1999.

[85] E. Batanero, P. Barral, M. Villalba, and R. Rodríguez, "Biodegradable poly (DL-lactide glycolide) microparticles as a vehicle for allergen-specific vaccines: a study performed with Ole e 1, the main allergen of olive pollen," Journal of Immunological Methods, vol. 259, no. 1-2, pp. 87-94, 2002.

[86] A. I. Camacho, R. Da Costa Martins, I. Tamayo et al., "Poly(methyl vinyl ether-co-maleic anhydride) nanoparticles as innate immune system activators," Vaccine, vol. 29, no. 41, pp. 7130-7135, 2011.

[87] P. Johansen, Y. Men, H. P. Merkle, and B. Gander, "Revisiting PLA/PLGA microspheres: an analysis of their potential in parenteral vaccination," European Journal of Pharmaceutics and Biopharmaceutics, vol. 50, no. 1, pp. 129-146, 2000.

[88] S. K. Mallapragada and B. Narasimhan, "Immunomodulatory biomaterials," International Journal of Pharmaceutics, vol. 364, no. 2, pp. 265-271, 2008.

[89] M. Murillo, C. Gamazo, J. M. Irache, and M. M. GoÑi, "Polyester microparticles as a vaccine delivery system for brucellosis: influence of the polymer on release, phagocytosis and toxicity," Journal of Drug Targeting, vol. 10, no. 3, pp. 211-219, 2002.

[90] M. L. Hans and A. M. Lowman, "Biodegradable nanoparticles for drug delivery and targeting," Current Opinion in Solid State and Materials Science, vol. 6, no. 4, pp. 319-327, 2002.

[91] A. Vila, H. Gill, O. McCallion, and M. J. Alonso, "Transport of PLA-PEG particles across the nasal mucosa: effect of particle size and PEG coating density," Journal of Controlled Release, vol. 98, no. 2, pp. 231-244, 2004.

[92] D. J. Bharali, V. Pradhan, G. Elkin et al., "Novel nanoparticles for the delivery of recombinant hepatitis B vaccine," Nanomedicine, vol. 4, no. 4, pp. 311-317, 2008.

[93] A. Vila, A. Sánchez, M. Tobío, P. Calvo, and M. J. Alonso, "Design of biodegradable particles for protein delivery," Journal of Controlled Release, vol. 78, no. 1-3, pp. 15-24, 2002.

[94] A. Vila, A. Sánchez, C. Évora, I. Soriano, O. McCallion, and M. J. Alonso, "PLA-PEG particles as nasal protein carriers: the influence of the particle size," International Journal of Pharmaceutics, vol. 292, no. 1-2, pp. 43-52, 2005.

[95] V. R. Sinha, K. Bansal, R. Kaushik, R. Kumria, and A. Trehan, "Poly-E-caprolactone microspheres and nanospheres: an overview," International Journal of Pharmaceutics, vol. 278, no. 1, pp. 1-23, 2004.

[96] S. R. Jameela, N. Suma, A. Misra, R. Raghuvanshi, S. Ganga, and A. Jayakrishnan, "Poly( $\varepsilon$-caprolactone) microspheres as 
a vaccine carrier," Current Science, vol. 70, no. 7, pp. 669-671, 1996.

[97] H. F. Florindo, S. Pandit, L. Lacerda, L. M. D. Gonçalves, H. O. Alpar, and A. J. Almeida, "The enhancement of the immune response against $\mathrm{S}$. equi antigens through the intranasal administration of poly- $\varepsilon$-caprolactone-based nanoparticles," Biomaterials, vol. 30, no. 5, pp. 879-891, 2009.

[98] P. Arbós, M. A. Arangoa, M. A. Campanero, and J. M. Irache, "Quantification of the bioadhesive properties of proteincoated PVM/MA nanoparticles," International Journal of Pharmaceutics, vol. 242, no. 1-2, pp. 129-136, 2002.

[99] K. Vandamme, V. Melkebeek, E. Cox et al., "Influence of

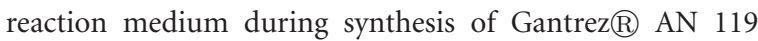
nanoparticles for oral vaccination," European Journal of Pharmaceutics and Biopharmaceutics, vol. 74, no. 2, pp. 202208, 2010.

[100] P. Arbós, M. A. Campanero, M. A. Arangoa, M. J. Renedo, and J. M. Irache, "Influence of the surface characteristics of PVM/MA nanoparticles on their bioadhesive properties," Journal of Controlled Release, vol. 89, no. 1, pp. 19-30, 2003.

[101] H. H. Salman, C. Gamazo, M. A. Campanero, and J. M. Irache, "Salmonella-like bioadhesive nanoparticles," Journal of Controlled Release, vol. 106, no. 1-2, pp. 1-13, 2005.

[102] K. Yoncheva, S. Gómez, M. A. Campanero, C. Gamazo, and J. M. Irache, "Bioadhesive properties of pegylated nanoparticles," Expert Opinion on Drug Delivery, vol. 2, no. 2, pp. 205-218, 2005.

[103] S. Gómez, C. Gamazo, B. S. Roman, M. Ferrer, M. L. Sanz, and J. M. Irache, "Gantrez $\AA$ AN nanoparticles as an adjuvant for oral immunotherapy with allergens," Vaccine, vol. 25, no. 29, pp. 5263-5271, 2007.

[104] S. Gómez, C. Gamazo, B. San Roman et al., "A novel nanoparticulate adjuvant for immunotherapy with Lolium perenne," Journal of Immunological Methods, vol. 348, no. 12, pp. 1-8, 2009.

[105] S. Gómez, C. Gamazo, B. S. Roman, C. Vauthier, M. Ferrer, and J. M. Irache, "Development of a novel vaccine delivery system based on gantrez nanoparticles," Journal of Nanoscience and Nanotechnology, vol. 6, no. 9-10, pp. 32833289, 2006.

[106] J. M. Irache, H. H. Salman, S. Gomez, S. Espuelas, and C. Gamazo, "Poly(anhydride) nanoparticles as adjuvants for mucosal vaccination," Frontiers in Bioscience, vol. 2, pp. 876$890,2010$.

[107] J. Ochoa, J. M. Irache, I. Tamayo, A. Walz, V. G. DelVecchio, and C. Gamazo, "Protective immunity of biodegradable nanoparticle-based vaccine against an experimental challenge with Salmonella Enteritidis in mice," Vaccine, vol. 25, no. 22, pp. 4410-4419, 2007.

[108] I. Tamayo, J. M. Irache, C. Mansilla, J. Ochoa-Repáraz, J. J. Lasarte, and C. Gamazo, "Poly(anhydride) nanoparticles act as active Th1 adjuvants through toll-like receptor exploitation," Clinical and Vaccine Immunology, vol. 17, no. 9, pp. 1356-1362, 2010.

[109] T. Akagi, T. Kaneko, T. Kida, and M. Akashi, "Preparation and characterization of biodegradable nanoparticles based on $\operatorname{poly}(\gamma$-glutamic acid) with L-phenylalanine as a protein carrier," Journal of Controlled Release, vol. 108, no. 2-3, pp. 226-236, 2005.

[110] S. Broos, K. Lundberg, T. Akagi et al., "Immunomodulatory nanoparticles as adjuvants and allergen-delivery system to human dendritic cells: implications for specific immunotherapy," Vaccine, vol. 28, no. 31, pp. 5075-5085, 2010.

[111] T. Uto, T. Akagi, K. Yoshinaga, M. Toyama, M. Akashi, and M. Baba, "The induction of innate and adaptive immunity by biodegradable poly ( $\gamma$-glutamic acid) nanoparticles via a TLR4 and MyD88 signaling pathway," Biomaterials, vol. 32, no. 22, pp. 5206-5212, 2011.

[112] B. S. Zolnik, Á. González-Fernández, N. Sadrieh, and M. A. Dobrovolskaia, "Minireview: nanoparticles and the immune system," Endocrinology, vol. 151, no. 2, pp. 458-465, 2010.

[113] D. H. Lee and I. J. Kang, "Drug delivery system using biodegradable nanoparticles carrier," Kona, vol. 24, pp. 159$166,2006$.

[114] R. Jayakumar, N. Nwe, S. Tokura, and H. Tamura, "Sulfated chitin and chitosan as novel biomaterials," International Journal of Biological Macromolecules, vol. 40, no. 3, pp. 175181, 2007.

[115] L. Illum, I. Jabbal-Gill, M. Hinchcliffe, A. N. Fisher, and S. S. Davis, "Chitosan as a novel nasal delivery system for vaccines," Advanced Drug Delivery Reviews, vol. 51, no. 1-3, pp. 81-96, 2001.

[116] K. Bowman and K. W. Leong, "Chitosan nanoparticles for oral drug and gene delivery," International Journal of Nanomedicine, vol. 1, no. 2, pp. 117-128, 2006.

[117] A. Masotti and G. Ortaggi, "Chitosan micro- and nanospheres: fabrication and applications for drug and DNA delivery," Mini-Reviews in Medicinal Chemistry, vol. 9, no. 4, pp. 463-469, 2009.

[118] K. Nagpal, S. K. Singh, and D. N. Mishra, "Chitosan nanoparticles: a promising system in novel drug delivery," Chemical and Pharmaceutical Bulletin, vol. 58, no. 11, pp. 1423-1430, 2010.

[119] I. M. Van der Lubben, J. C. Verhoef, G. Borchard, and H. E. Junginger, "Chitosan for mucosal vaccination," Advanced Drug Delivery Reviews, vol. 52, no. 2, pp. 139-144, 2001.

[120] G. Borchard, "Chitosans for gene delivery," Advanced Drug Delivery Reviews, vol. 52, no. 2, pp. 145-150, 2001.

[121] H. L. Jiang, Y. K. Kim, R. Arote et al., "Chitosan-graftpolyethylenimine as a gene carrier," Journal of Controlled Release, vol. 117, no. 2, pp. 273-280, 2007.

[122] W. E. Rudzinski and T. M. Aminabhavi, "Chitosan as a carrier for targeted delivery of small interfering RNA," International Journal of Pharmaceutics, vol. 399, no. 1-2, pp. 1-11, 2010.

[123] A. V. Il'ina and V. P. Varlamov, "Chitosan-based polyelectrolyte complexes: a review," Applied Biochemistry and Microbiology, vol. 41, no. 1, pp. 5-11, 2005.

[124] A. Vila, A. Sánchez, K. Janes et al., "Low molecular weight chitosan nanoparticles as new carriers for nasal vaccine delivery in mice," European Journal of Pharmaceutics and Biopharmaceutics, vol. 57, no. 1, pp. 123-131, 2004.

[125] K. Roy, H. Q. Mao, S. K. Huang, and K. W. Leong, "Oral gene delivery with chitosan-DNA nanoparticles generates immunologic protection in a murine model of peanut allergy," Nature Medicine, vol. 5, no. 4, pp. 387-391, 1999.

[126] F. Li, L. Wang, X. M. Jin, C. H. Yan, S. Jiang, and X. M. Shen, "The immunologic effect of TGF-betal chitosan nanoparticle plasmids on ovalbumin-induced allergic BALB/c mice," Immunobiology, vol. 214, no. 2, pp. 87-99, 2009.

[127] S. Zhu, F. Qian, Y. Zhang, C. Tang, and C. Yin, "Synthesis and characterization of PEG modified Ntrimethylaminoethylmethacrylate chitosan nanoparticles," European Polymer Journal, vol. 43, no. 6, pp. 2244-2253, 2007. 
[128] S. A. Agnihotri, N. N. Mallikarjuna, and T. M. Aminabhavi, "Recent advances on chitosan-based micro- and nanoparticles in drug delivery," Journal of Controlled Release, vol. 100, no. 1, pp. 5-28, 2004.

[129] A. Domard, M. Rinaudo, and C. Terrassin, "New method for the quaternization of chitosan," International Journal of Biological Macromolecules, vol. 8, no. 2, pp. 105-107, 1986.

[130] A. F. Kotze, M. M. Thanou, H. L. Luessen, A. B. G. De Boer, J. C. Verhoef, and H. E. Junginger, "Effect of the degree of quaternization of N-trimethyl chitosan chloride on the permeability of intestinal epithelial cells (Caco-2)," European Journal of Pharmaceutics and Biopharmaceutics, vol. 47, no. 3, pp. 269-274, 1999.

[131] S. Mangal, D. Pawar, N. K. Garg et al., "Pharmaceutical and immunological evaluation of mucoadhesive nanoparticles based delivery system(s) administered intranasally," Vaccine, vol. 29, no. 31, pp. 4953-4962, 2011.

[132] O. Borges, G. Borchard, J. C. Verhoef, A. De Sousa, and H. E. Junginger, "Preparation of coated nanoparticles for a new mucosal vaccine delivery system," International Journal of Pharmaceutics, vol. 299, no. 1-2, pp. 155-166, 2005.

[133] O. Borges, M. Silva, A. de Sousa, G. Borchard, H. E. Junginger, and A. Cordeiro-da-Silva, "Alginate coated chitosan nanoparticles are an effective subcutaneous adjuvant for hepatitis B surface antigen," International Immunopharmacology, vol. 8, no. 13-14, pp. 1773-1780, 2008.

[134] O. Borges, J. Tavares, A. de Sousa, G. Borchard, H. E. Junginger, and A. Cordeiro-da-Silva, "Evaluation of the immune response following a short oral vaccination schedule with hepatitis B antigen encapsulated into alginate-coated chitosan nanoparticles," European Journal of Pharmaceutical Sciences, vol. 32, no. 4-5, pp. 278-290, 2007.

[135] J. Ho, F. M. N. Al-Deen, A. Al-Abboodi et al., "N,N'Carbonyldiimidazole-mediated functionalization of superparamagnetic nanoparticles as vaccine carrier," Colloids and Surfaces B, vol. 83, no. 1, pp. 83-90, 2011.

[136] T. Fifis, A. Gamvrellis, B. Crimeen-Irwin et al., "Sizedependent immunogenicity: therapeutic and protective properties of nano-vaccines against tumors," Journal of Immunology, vol. 173, no. 5, pp. 3148-3154, 2004.

[137] R. Song and C. V. Harding, "Roles of proteasomes, transporter for antigen presentation (TAP), and $\beta 2$-microglobulin in the processing of bacterial or particulate antigens via an alternate class I MHC processing pathway," Journal of Immunology, vol. 156, no. 11, pp. 4182-4190, 1996.

[138] L. Vidard, M. Kovacsovics-Bankowski, S. K. Kraeft, L. B. Chen, B. Benacerraf, and K. L. Rock, "Analysis of MHC class II presentation of particulate antigens by B lymphocytes," Journal of Immunology, vol. 156, no. 8, pp. 2809-2818, 1996.

[139] L. Zhang, G. Widera, S. Bleecher, D. A. Zaharoff, B. Mossop, and D. Rabussay, "Accelerated immune response to DNA vaccines," DNA and Cell Biology, vol. 22, no. 12, pp. 815-822, 2003.

[140] D. M. Mahvi, F. S. Shi, N. S. Yang et al., "Immunization by particle-mediated transfer of the granulocyte-macrophage colony-stimulating factor gene into autologous tumor cells in melanoma or sarcoma patients: report of a phase I/IB study," Human Gene Therapy, vol. 13, no. 14, pp. 1711-1721, 2002.

[141] S. Parween, P. K. Gupta, and V. S. Chauhan, "Induction of humoral immune response against PfMSP-119 and PvMSP119 using gold nanoparticles along with alum," Vaccine, vol. 29, no. 13, pp. 2451-2460, 2011.

[142] Y. J. Kwon, S. M. Standley, S. L. Goh, and J. M. J. Fréchet, "Enhanced antigen presentation and immunostimulation of dendritic cells using acid-degradable cationic nanoparticles," Journal of Controlled Release, vol. 105, no. 3, pp. 199-212, 2005.

[143] Y. J. Kwon, E. James, N. Shastri, and J. M. J. Fréchet, "In vivo targeting of dendritic cells for activation of cellular immunity using vaccine carriers based on $\mathrm{pH}$-responsive microparticles," Proceedings of the National Academy of Sciences of the United States of America, vol. 102, no. 51, pp. 18264-18268, 2005. 

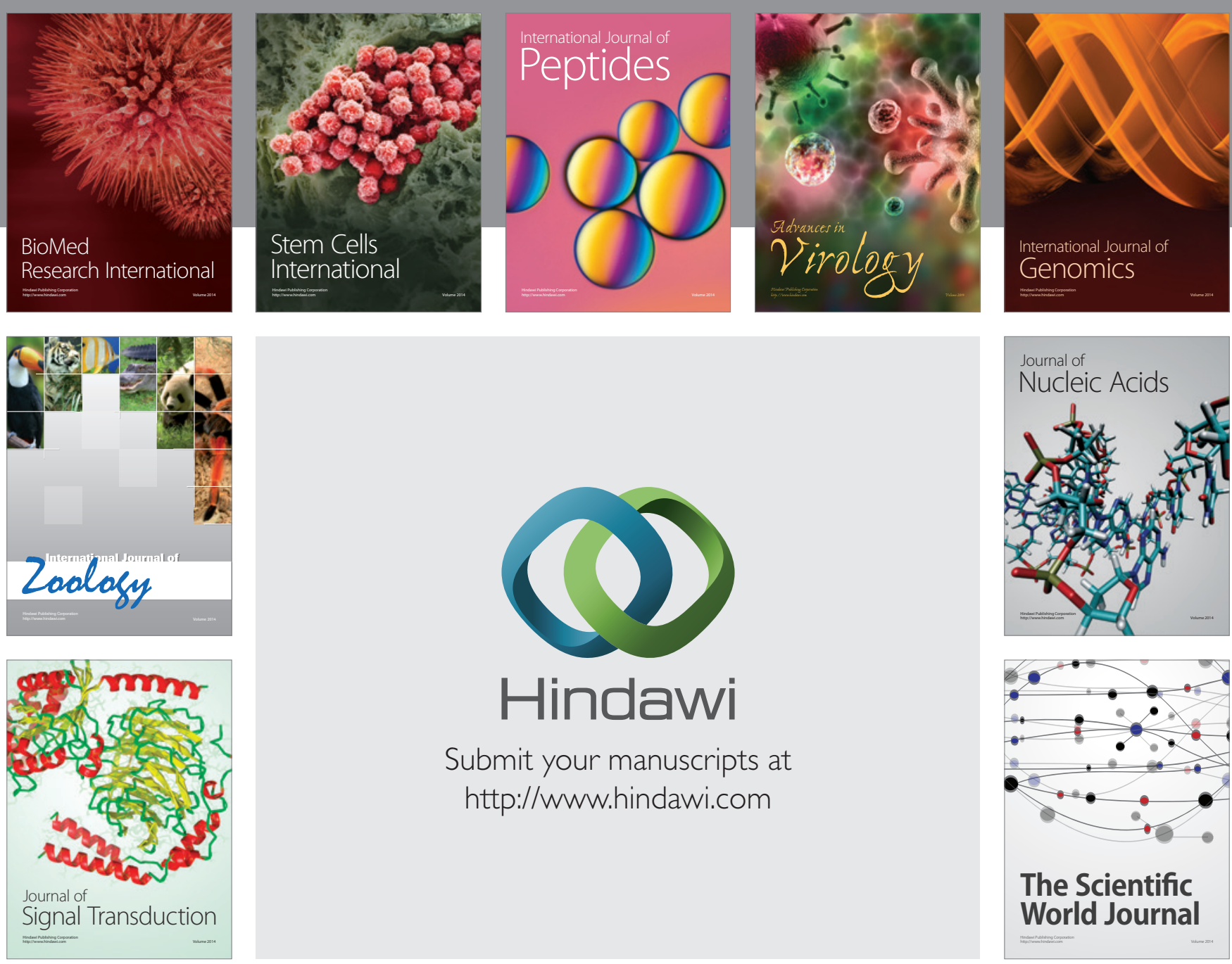

Submit your manuscripts at

http://www.hindawi.com
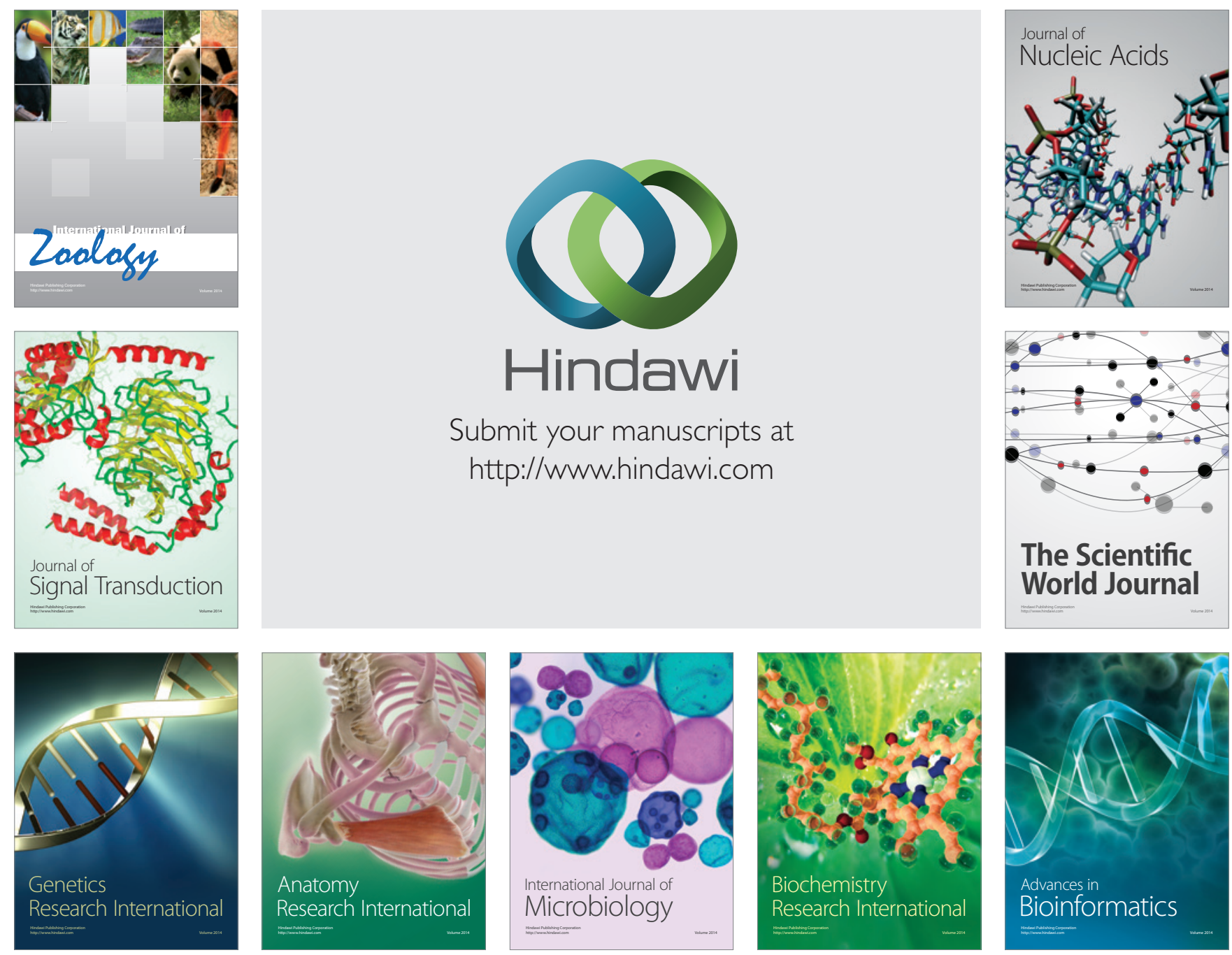

The Scientific World Journal
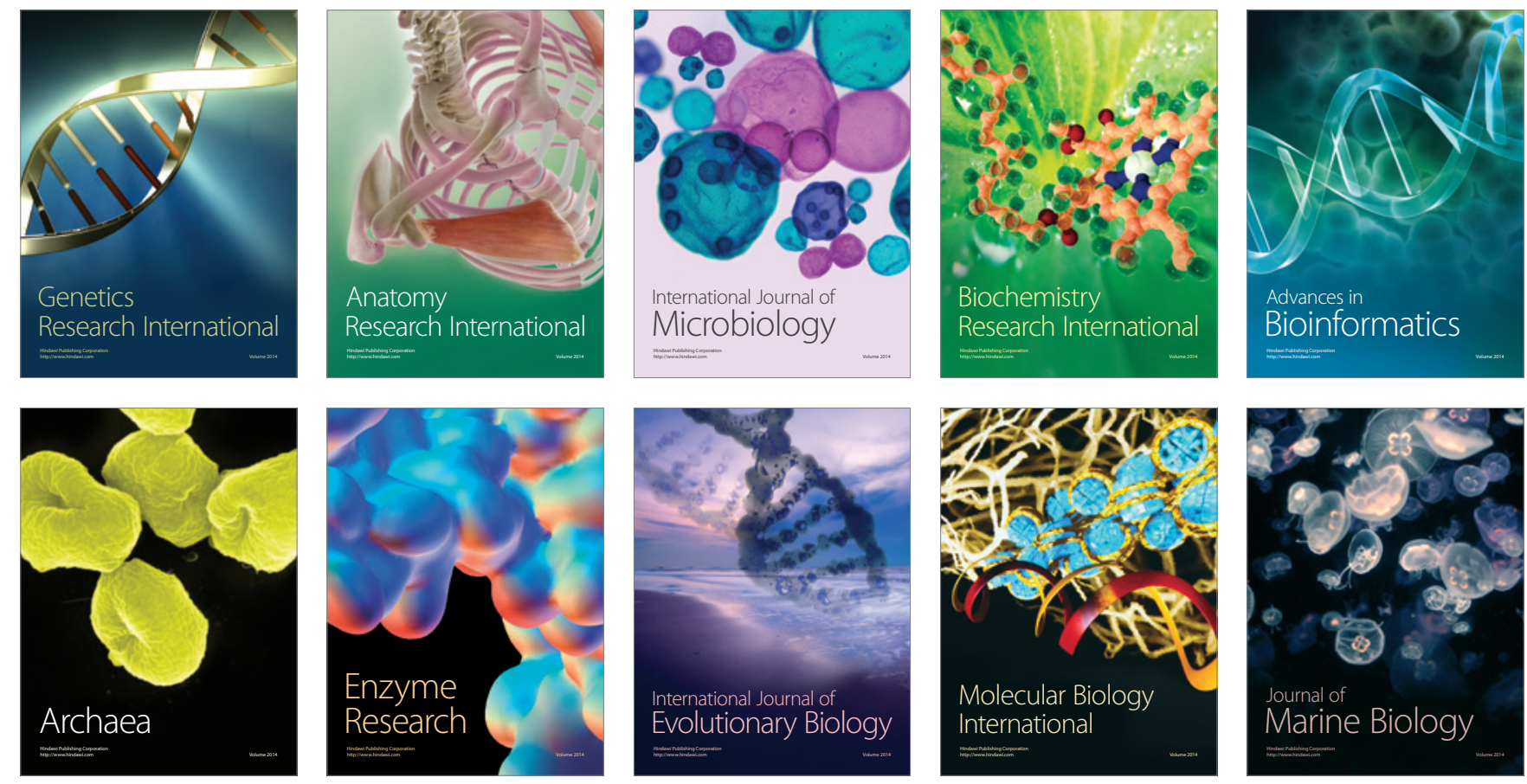